\title{
Potential of the system of rice intensification for systemic improvement in rice production and water use: the case of Andhra Pradesh, India
}

\author{
Ravindra Adusumilli · S. Bhagya Laxmi
}

Received: 17 September 2010/Revised: 7 October 2010/Accepted: 8 October 2010/Published online: 24 October 2010

(C) The Author(s) 2010. This article is published with open access at Springerlink.com

\begin{abstract}
As opportunities to enhance the irrigation base for raising food production in the country are dwindling, India needs a more concerted effort to increase the efficiency and productivity of its irrigation systems. This study, based on an analysis of experience from the state of Andhra Pradesh, addresses the potential of the System of Rice Intensification (SRI) to contribute to systemic corrections in present paddy cultivation, both with regard to agronomic productivity and irrigation water use efficiency. This study points to the considerable increase in rice productivity and farmer incomes, which is being achieved in Andhra Pradesh with substantial reduction in irrigation water application, labor, and seed costs through utilization of SRI methods. Potential public savings on water and power costs could be drawn upon not only for promoting SRI but also to effect systemic corrections in the irrigation sector, to mutual advantage.
\end{abstract}

Keywords Groundwater use · Irrigation efficiency · System of Rice Intensification - Water requirements

\section{Introduction}

Andhra Pradesh, a southern Indian state, contributes about $13 \%$ of the rice produced in India. Since 2000, the area

R. Adusumilli $(\bowtie) \cdot$ S. Bhagya Laxmi

Watershed Support Services and Activities Network

(WASSAN), Hyderabad, India

e-mail: raviwn@gmail.com

S. Bhagya Laxmi

e-mail: bhagyawn@gmail.com

R. Adusumilli

Development Economics Group, Wageningen University,

Wageningen, Netherlands devoted to rice and the resulting production in the state have dropped off substantially, as seen in Fig. 1. The main sources of irrigation in the state are canal irrigation systems, tanks, and tubewells. Despite some increases in the command area served by the latter source, there has been an overall reduction in irrigated area in recent years (Table 1). Most retrenchment of area has occurred in canal and tank irrigation systems. Canal irrigation projects are operating at an efficiency level as low as $35 \%$, and about $11 \%$ of the canal-irrigated area has become saline and waterlogged (Gulati 2007).

According to its records, Andhra Pradesh has 77,472 tanks, many of them constructed in historical times. They have a command area of 1.75 million hectares. Of these, $24,170(31 \%)$ are presently out of use, and many others are in a state of disrepair that reduces their service area and functioning, mainly due to failures of institutional and management systems. Increasing salinity is a major problem in many tank command areas (CAD 2008).

The large-scale shift from canal and tank irrigation to reliance on wells has placed stressful demands on the state's groundwater resources, with extraction exceeding recharge rates in several parts of Andhra Pradesh. About $43 \%$ of the state's mandals (local administrative units) are classified as over-exploited, critical, or near-critical with respect to their levels of groundwater extraction as a proportion of recharge (Jain et al. 2009). The failure of many tubewells to support crop production sufficiently and the consequent losses of income and increased debt burden for farmers have contributed to a growing number of suicides in the state, adding a tragic human dimension to the hydrological crisis (Moyna and Mishra 2010). More important than present numbers, still in contention, is that this crisis in the irrigation sector of Andhra Pradesh is likely to deepen in the course of time if no corrective steps are taken. 


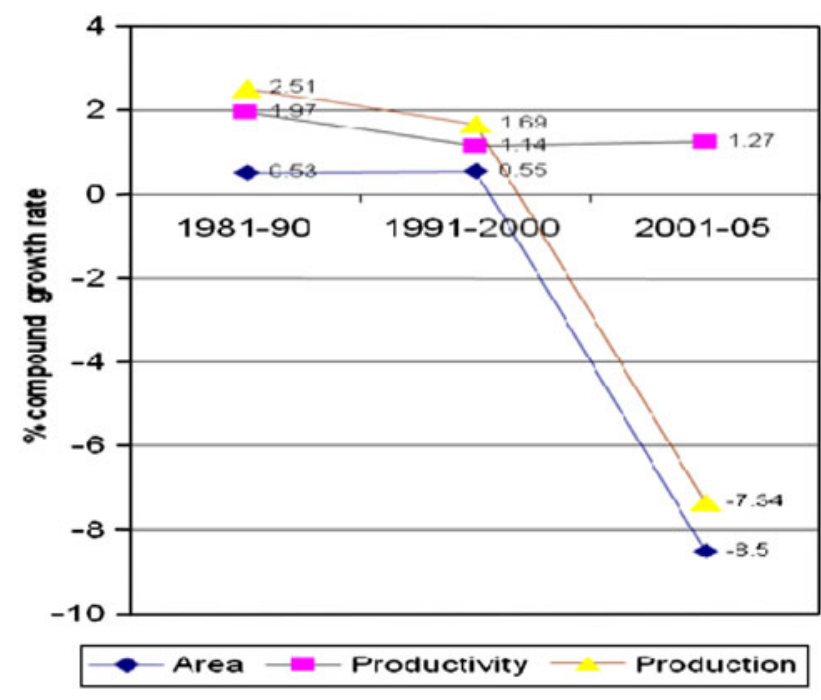

Fig. 1 Annual percentage changes in rice area, production, and productivity in Andhra Pradesh

Table 1 Compound annual rate of growth (or decline) in irrigated area in Andhra Pradesh state, by source of irrigation water, 1995-2005

\begin{tabular}{ll}
\hline Water source & $\begin{array}{l}\text { Annual percent change } \\
\text { in irrigated area }\end{array}$ \\
\hline Canals & -6.5 \\
Tanks & -8.3 \\
Tube wells & 4.4 \\
Other wells & -7.2 \\
Total wells & -0.5 \\
Other sources & -7.2 \\
Total & -4.0 \\
\hline
\end{tabular}

Source: Rama Rao et al. (2008)

Rice is the major crop under canal, tank, and tubewell irrigation systems, with groundwater-based systems now constituting $50 \%$ of the gross irrigated area in the state. The normal practices of rice cultivation include transplanting seedlings about 25 days old, with a seed rate of $60-75 \mathrm{~kg} \mathrm{ha}^{-1}$, and continuous inundation of water until the grain filling stages.

The canal and tank irrigation systems have been traditionally designed for such normal rice cultivation practices, and tubewell irrigation makes the same assumptions. AP state has a policy of supplying electricity to agriculture with no charge, setting a cap on supply for farmers of $7 \mathrm{~h} \mathrm{day}^{-1}$. This supply is generally given in two shifts, one of which is in the night on a rotation basis. Farmers have started using automatic starters so that their pumps are operational whenever the power supply resumes. The irrigation practice of inundation fits into this system well, with automatic starters minimizing farmers' inconvenience. However, this has resulted in high irrigation inefficiencies.
The disarray of the irrigation systems in the state, with ensuing low water productivity, has serious implications to future rice production. Linkage between irrigation systems' functioning and rice production has been missed in several government programs, such as National Food Security Mission (NFSM), which aim to enhance rice production in the country for national food security. The NFSM strategy relies primarily on extending hybrid rice technology, fertilizers, and micronutrient applications (Government of India 2007).

The System of Rice Intensification (SRI), introduced into Andhra Pradesh in 2003 with systematic evaluation in on-farm comparison trials across all districts of the state (Satyanarayana et al. 2006), takes on greater significance within the above context of water limitations. Although SRI has not spread across the state on a large scale, experiences in a number of areas can be assessed for its potential to contribute to the policy objectives. It is particularly important to consider the extent to which the introduction of SRI can contribute to systemic corrections in tubewell and tank irrigation systems and to improving water productivity in an era when the effects of climate change are making this more urgent.

\section{Methods}

The System of Rice Intensification as promoted and followed in this study included the transplanting of younger seedlings, usually 8-14 days of age (the two-leaf stage), with square spacing of $25 \mathrm{~cm}$ (using a marker), mostly single seedlings per hill (at times two), alternate wet and dry irrigation, and mechanical weeding, 1-3 times before canopy closure using a rotary weeder.

These are the practices followed as much as possible by the farmers in the sample, although there was often some variation with regard to irrigation. Some farmers usually kept their field water at saturation level, while some others irrigated their field after seeing hairline cracks in the soil surface, and some at times kept a thin film of water on the field. In any case, the water regime followed was significantly different from the conventional practice of continuous flooding. The promoting organization also insisted on farmers making some addition of organic matter to their fields in terms of farmyard manure or green leaf compost. Conventional practice consists mostly of raising seedlings in (usually flooded) nurseries for 20-30 days before transplanting, with no regular spacing between clumps of plants, manual weeding as necessary, and inundation of the field with water.

This article compares the performance of SRI and conventional rice fields in two mandals (subdistricts) of Mahabubnagar district of Andhra Pradesh. The data are 
from the 2009-2010 rabi (dry) season. In these mandals, SRI has been promoted over the past 4 years by the Federations of SHGs (i.e., self-help groups) with support from the NGO known as WASSAN.

This study was not conducted with fully random selection and control plots. It was rather an effort by the program to understand what if any impacts the new methods were having on farmers' productivity; also, whether water savings were being achieved. From a list of farmers who were practicing SRI in two villages where the program was active, a random sample of 55 SRI-using farmers was drawn. Then an equal number of farmers cultivating still with conventional methods nearby those 55 farmers was selected. As there was no complete listing of conventional farmers, no proper random selection was possible. However, farmers were chosen for inclusion in the comparative analysis because they were similar to the SRI farmers in the sample in terms of landholding, soils, education, etc.

The two sets of farmers whose practices and results were studied were thus quite comparable, although not formally randomized. The latter set was regarded as controls for the sake of comparison. At the end of the season, six of the farmers using conventional methods and seven SRI farmers had to be dropped from the analysis because their data were incomplete. Thus, there were full sets of data for 49 conventional and 48 SRI farmers. The data from the SRI farmer sample were collected over the whole season, while the data on conventional paddy production were collected at the end of the season. The landholdings of the two sets of farmers are reported in Table 2, showing no significant difference between them in terms of land size.

The mean area under paddy cultivation for the total sample was 0.66 ha, with SRI farmers having slightly, but non-significantly more area, 0.74 ha. Possibly they were farmers who took rice cultivation more seriously. That most of the farmers in the sample are small to marginal farmers is seen from their mean landholding size of 1.73 ha (Table 2). There was no significant difference seen in the total landholding areas of the sampled SRI and conventional farmers, although SRI farmers appeared to have, if anything, slightly smaller holdings. Notably, the SRI farmers studied had about three-fourths of their paddy area under SRI management.
Detailed data on water consumption could not be obtained as it was difficult to measure water volumetrically in the field situation. To derive a first approximation of the impact of SRI methods on irrigation water use, the number of pumping hours used for growing the rice crop was selected as a proxy variable to understand the differences in water use between SRI and conventional paddy cultivation. This estimate was arrived at from interviews with representative SRI and conventional farmers, 7 and 5, respectively, to determine whether water applications were indeed reduced, although it could not be stated how much difference in volume of water application was involved.

Standard statistical tools were used to analyze the differences between conventional and SRI farmers. Analyses were also undertaken of technical options within SRI. This article presents the results of the analysis and considers policy implications of what was found from that analysis.

\section{Results and discussion}

Yield, cost, and profitability comparisons

Table 3 presents comparisons of means of grain and straw yields for SRI and conventional paddy cultivation, along with differences in expenditures and returns $\mathrm{ha}^{-1}$. The value of grain yield and both gross and net returns were calculated at a constant grain price of Rs. 10,000 ton ${ }^{-1}$. Table 4 reports on differences in expenditures made on the major categories of production inputs according to method of cultivation.

For this sample of farmers, SRI gave a statistically significant yield advantage of $18 \%$ over conventional paddy cultivation, as shown in Table 3 . Together with a substantial decrease in total expenditures, Rs. 9,187 ha ${ }^{-1}$ (32\%), this yield increase had a marked impact on farmers' net return from SRI cultivation, 52\% higher than conventional returns.

Different categories of production cost are compared in Table 4. Reduction in expenditure was contributed to most by a $37 \%$ reduction in the labor costs for transplantation, and by a $51 \%$ reduction in the labor for weeding. Seed cost was reduced by $90 \%$, but this saving was only third largest

Table 2 Landholding details for the sampled farmers, in hectares

\begin{tabular}{|c|c|c|c|c|c|c|c|c|}
\hline & \multicolumn{2}{|c|}{ Conventional } & \multicolumn{2}{|l|}{ SRI } & \multicolumn{2}{|l|}{ Total } & \multicolumn{2}{|c|}{ Comparison of means } \\
\hline & Mean & SD & Mean & SD & Mean & $\mathrm{SD}$ & $F$ statistic & Significance level \\
\hline Total land area & 1.80 & 0.64 & 1.65 & 1.09 & 1.73 & 0.89 & 0.68 & 0.411 \\
\hline Total area under paddy & 0.58 & 0.30 & 0.74 & 0.44 & 0.66 & 0.38 & 4.00 & 0.048 \\
\hline Sampled area & 0.57 & 0.27 & 0.54 & 0.27 & 0.57 & 0.27 & 0.27 & 0.61 \\
\hline
\end{tabular}


Table 3 Differences in expenditure, yield, and economic returns for alternative cultivation methods

\begin{tabular}{|c|c|c|c|c|c|}
\hline \multirow[t]{2}{*}{ Parameter } & \multirow{2}{*}{$\begin{array}{l}\text { Conventional } \\
\text { Mean }\end{array}$} & \multirow{2}{*}{$\begin{array}{l}\text { SRI } \\
\text { Mean }\end{array}$} & \multirow{2}{*}{$\begin{array}{l}\text { SRI compared } \\
\text { to conventional } \\
\text { Difference }\end{array}$} & \multicolumn{2}{|c|}{ Comparison of means: conventional and SRI } \\
\hline & & & & F statistic & Level of significance \\
\hline Total expenditure (Rs. ha ${ }^{-1}$ ) & $28,476(10,622)$ & $19,289(5,851)$ & $-9,187[-32 \%]$ & 28.38 & 0.000 \\
\hline Grain yield $\left(\mathrm{t} \mathrm{ha}^{-1}\right)$ & $4.55(0.65)$ & $5.39(1.06)$ & $8.38[18 \%]$ & 22.8 & 0.000 \\
\hline Straw yield $\left(\mathrm{t} \mathrm{ha}{ }^{-1}\right)$ & $2.87(1.21)$ & $2.32(1.53)$ & $-5.45[-19 \%]$ & 3.96 & 0.050 \\
\hline Straw value $\left(\right.$ Rs. ha $\left.{ }^{-1}\right)$ & $10,261(4,825)$ & $6,825(3,000)$ & $-3,436[-34 \%]$ & 18.11 & 0.000 \\
\hline Grain value $\left(\mathrm{Rs} . \mathrm{ha}^{-1}\right)^{*}$ & $45,472(6,524)$ & $53,853(10,623)$ & $8,381[18 \%]$ & 22.8 & 0.000 \\
\hline Gross returns $\left(\text { Rs. ha }{ }^{-1}\right)^{*}$ & $55,732(8,861)$ & $60,678(12,002)$ & $4,946[9 \%]$ & 5.53 & 0.021 \\
\hline Net returns $\left(\text { Rs. ha }{ }^{-1}\right)^{*}$ & $27,257(8,508)$ & $41,389(11,619)$ & $14,132[52 \%]$ & 48.44 & 0.000 \\
\hline
\end{tabular}

Notes: Figures in parenthesis are standard deviations; figures in brackets are the differences, in percent, between SRI and conventional results

* Indicates highly significant

Table 4 Input expenditures in SRI and conventional rice cultivation, in Rs. ha ${ }^{-1}$

\begin{tabular}{llllll}
\hline Input & Conventional & SRI & \multicolumn{2}{l}{ SRI over conventional } & $F$ value \\
& Mean & Mean & Amount & $\%$ & \\
\hline Fertilizer (manure + chemical) & $2,849(1,268)$ & $3,115(1,284)$ & 266 & 9 & $1.09^{*}$ \\
Seeds & $1,422(432)$ & $148(108)$ & $-1,274$ & -90 & 402.28 \\
Pesticide & $77(216)$ & $8(53)$ & -69 & -90 & $4.73^{*}$ \\
Nursery & $946(360)$ & $412(238)$ & -534 & -56 & 75.82 \\
Transplantation & $4,891(1,398)$ & $3,062(1,302)$ & $-1,829$ & -37 & 45.76 \\
Weeding (mechanical & $3,484(1,637)$ & $1,692(979)$ & $-1,792$ & -51 & 43.68 \\
$\quad$ and hand weeding included) & & & & & \\
Total expenditure & $28,476(10,622)$ & $19,289(5,851)$ & $-9,187$ & -32 & 28.38 \\
\hline
\end{tabular}

contributor to lower costs of production. The differences in the means for these three categories of expenditure between SRI and conventional practice were highly significant (Table 4). Nursery costs were 56\% less than with conventional cultivation, but this was not a large share of the total reduction in input costs.

That the straw yield with SRI was lower than with conventional methods, by $19 \%$ (Table 3 ), reflects a higher grain-to-biomass (Harvest Index) ratio. Conversion of local measurements into comparable quantities presented some difficulties because the local metrics used for volume of straw differ across villages, as do those for weight. Thus, we recognize that the figures on quantities of straw presented in Table 3 may contain some error. However, the relative results are consistent with farmers' observations during the season. Figure 2 summarizes in graphic form the relative differences between SRI and conventional paddy farms according to these parameters.

Note that fertilizer and pesticide costs were not significantly different between the two systems (Table 4). The promoting organization insisted on the addition of organic manure for all farms, and there was low overall pest incidence during the season. These considerations may explain the lack of any variation on these inputs between the two systems.

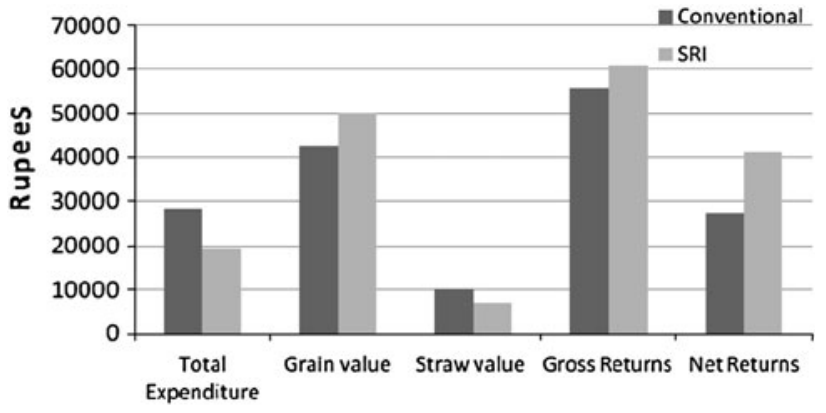

Fig. 2 Comparison of expenditure and returns in SRI and conventional paddy production

The question of 'labor-intensity' with SRI

The results of the survey call into the question the popular notion that SRI is a labor-intensive innovation (Moser and Barrett 2003). Analysis of farmers' experience in Andhra Pradesh challenges this conclusion, since in our study, farmers using SRI practices had a $43 \%$ reduction in their overall labor costs, with disaggregated cost reductions shown in Fig. 3.

Why is there a perception that SRI is more laborintensive when data show otherwise? Several factors could 


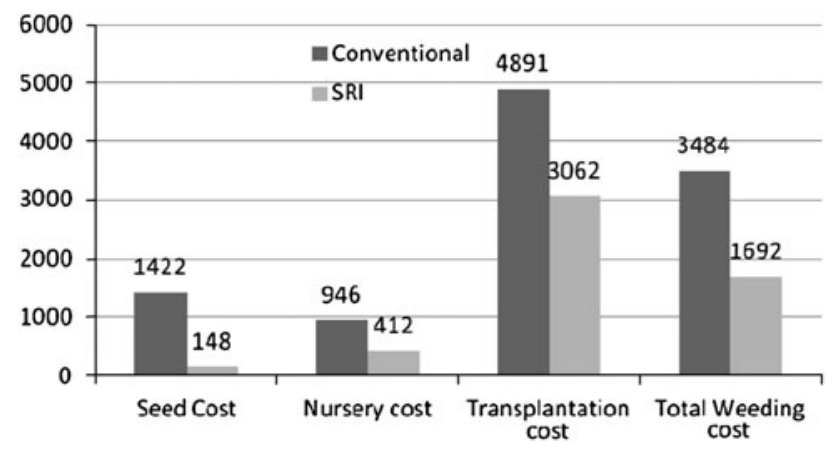

Fig. 3 Comparison of input costs in SRI and conventional paddy production

contribute to this. In comparison with conventional rice cultivation, SRI does demand more management effort, if not more labor time. Farmers need to pay more attention to crop establishment, to the use of younger seedlings, the need for timely transplantation and timely weeding, and better water management. So some additional time is involved with SRI that is not considered in standard input accounting procedures. This is to say that SRI is more management-intensive if not more labor-intensive.

Other considerations are that although labor becomes more productive in SRI practice, it requires the development of some new skills, especially for transplanting and mechanical weeding, these take some time for learning. Also, there are some gender shifts in SRI rice growing that may encounter resistance, such as when men take over weeding, operating push weeders in place of women who previously did hand weeding, because in many communities mechanical work is considered to be men's work. Farmers thus may need to make some additional efforts to master new skills or to negotiate new labor agreements. As there is no precedent of mechanical weeding, the contract rates for weeding were not defined. Initial perceptions that SRI labor is more difficult may come from farmers' need to negotiate new terms for labor, and to give instruction on the new methods and to monitor their use. This, however, is not intrinsic and should recede as a problem and a cost.

We refer to a study done in 2004 by Tamil Nadu Agricultural University researchers, who persuaded 100 farmers to use SRI and conventional practices on side-byside plots (Satyanarayana et al. 2006). It was determined that men's labor ha ${ }^{-1}$ went up $64 \%$ on SRI plots, while women's labor inputs fell by $26 \%$. Why? Because men took over the weeding operations, now seen as 'men's work.' This added 38 man-days $\mathrm{ha}^{-1}$ to their labor for rice cultivation, while women by giving up hand weeding reduced their labor by 80 days $\mathrm{ha}^{-1}$. The overall reduction in labor inputs for the 100 farmers was $8 \%$. This was the same reduction found in an evaluation of rainfed SRI in West Bengal state by Sinha and Talati (2007), researchers from the India programme of the International Water Management Institute (IWMI).

Why should men accept this increased labor burden? For one thing, their doing weeding mechanically freed up twice as much time as women spend on hand weeding previously. Further, SRI cultivation cut men's nursery labor time in half, and reduced their irrigation time by $20 \%$. Switching to SRI methods gave a significant financial reward, more than doubling the net income $\mathrm{ha}^{-1}$ from rice farming: from $\$ 242$ with conventional practices, to $\$ 519$ with SRI management. This benefit was not received until harvest time, but it was substantial.

TNAU researchers calculated that with SRI management, overall costs of production declined from $\$ 466$ to $\$ 414 \mathrm{ha}^{-1}$, while gross revenue, reflecting a $32 \%$ increase in average yield, went from $\$ 708$ to $\$ 933 \mathrm{ha}^{-1}$. Note that these results were with first-time SRI users, so with instruction and monitoring, total labor costs can decline in the first year. They could also become greater in future years once the methods are fully understood and utilized.

The extra time taken to master new techniques and to negotiate new divisions of rice production labor are essentially transitory adjustments, but they could lie behind the notion that SRI is 'more labor-intensive' even if there is a reduction in labor costs. It is to be expected that farmerlabor market adjustments will take a little time to work out as these are affected by the scale of adoption of an innovation and by the level of comfort attained by laborers with the new forms of work.

Water use with SRI under tubewell irrigation systems

Water use in SRI at field level is complicated to measure. An attempt was made to arrive at a first approximation of the differences in water use between SRI and conventional rice production. Twelve farmers under tubewell irrigation were selected for in-depth interviews and data generation. Of these, seven were practicing SRI and five were conventional paddy farmers. These sample farmers were selected in such a way that their tubewells represented similar conditions in terms of water pump discharge and power rating. Data were collected from individual farmers after the harvest on their method of watering, their number of irrigations, and the number of pumping hours for each irrigation required in different crop growth stages.

Rationing of electricity by the Government of Andhra Pradesh provides a fixed number of hours, seven, provided in two shifts. This enabled researchers to make straightforward computation of the number of pumping hours. Andhra Pradesh government provides free electricity to farmers, which eliminates any incentive to economize on water use. The crop growth stages inquired about were based on local understandings of crop growth periods. The 
data pertain to the 2009-2010 rabi season, a year with relatively good rainfall and substantial groundwater recharge.

The number of pumping hours was treated as a proxy for actual water use. As the selected tubewells were similar in discharge, an attempt was also made to estimate the water use, assuming that each tubewell had a discharge of $25,0001 \mathrm{~h}^{-1}$. This was a crude approximation, but it was based on previous tubewell-discharge measurements made by our NGO WASSAN. The absolute values thus arrived at may have considerable margin of error, but the relative differences between SRI and conventional practice can serve a reasonable first approximation.

Figure 4 presents comparisons of the number of irrigations and the number of pumping hours at each stage of the crop growth, under conventional and SRI management. There was not much difference during the land preparation stage, as no special water-saving tillage methods were employed in SRI for the season. Table 5 presents detailed comparisons of irrigation/water usage.

Farmers interviewed who followed the conventional practice of inundation used, by our calculations, nearly three times greater volume of water during the rabi season compared to the generally suggested crop-water requirement of $12,400 \mathrm{~m}^{3} \mathrm{ha}^{-1}$. Uncertainty about the timing of electricity supply has led many farmers to use automatic starters, which pump to a maximum whenever power is available. For fear of a breakdown or stoppage in power supply, excess volumes of water are thus commonly kept in the fields.

The number of irrigations and number of pumping hours $\mathrm{ha}^{-1}$ in SRI fields were $52 \%$ less than in the conventional paddy, calculating water pumped from a tubewell with an electric submersible motor of 5HP power rating. Mahendra Kumar et al. (2010) have reported an observed reduction in water use of $38 \%$ in on-station SRI trials in 25 locations across India. The water saving that can be obtained with SRI management in the field situation, where little effort is made to economize on water applications, seems to be substantially higher than in such controlled experimental fields.

It appears that Andhra Pradesh farmers, at least those cultivating under Mahbubnagar local conditions, could skip half of their current number of irrigations in the crop season. SRI also might bring some discipline to tubewell irrigation systems as SRI farmers have reason to switch off their electric motors when water is not needed or to expand their irrigated area. The major irrigation savings with SRI irrigation management was around the first weeding, panicle initiation, and panicle development stages. Adherence to all of the principles of SRI, with only slight variations, by giving higher yields and better returns would reinforce motivation for controlling irrigation and making savings in irrigation water.

Operationally, irrigation water drained from one field can be used for irrigating the next plot. Figure 5 presents the cumulative irrigation water applied in SRI and conventional systems. The results of this study bring out the large potential with SRI for reducing the quantum of water use and also to bring in purposeful management in irrigation water usage. Several of the farmers in the survey reported extension of their area under paddy as a result of SRI savings in water. These preliminary results are very promising; but irrigation management with SRI needs more systematic study to determine how to make use of SRI as a lever for introducing management reforms in groundwater and surface irrigation systems.

Savings in electricity

Each hectare of SRI under tubewell irrigation in the study area saved about 845 pumping hours in one season compared to the conventional paddy. This amounts to $3,151 \mathrm{kWh}$ of savings in electricity consumption (assuming 5 HP pumps). Even at a cost of Rs. 4 per unit (kWh), the state will save about Rs. 12,607 on every ha of paddy
Fig. 4 Comparisons of tubewell irrigation amounts between SRI and conventional rice production, according to crop growth stage, according to farmer information

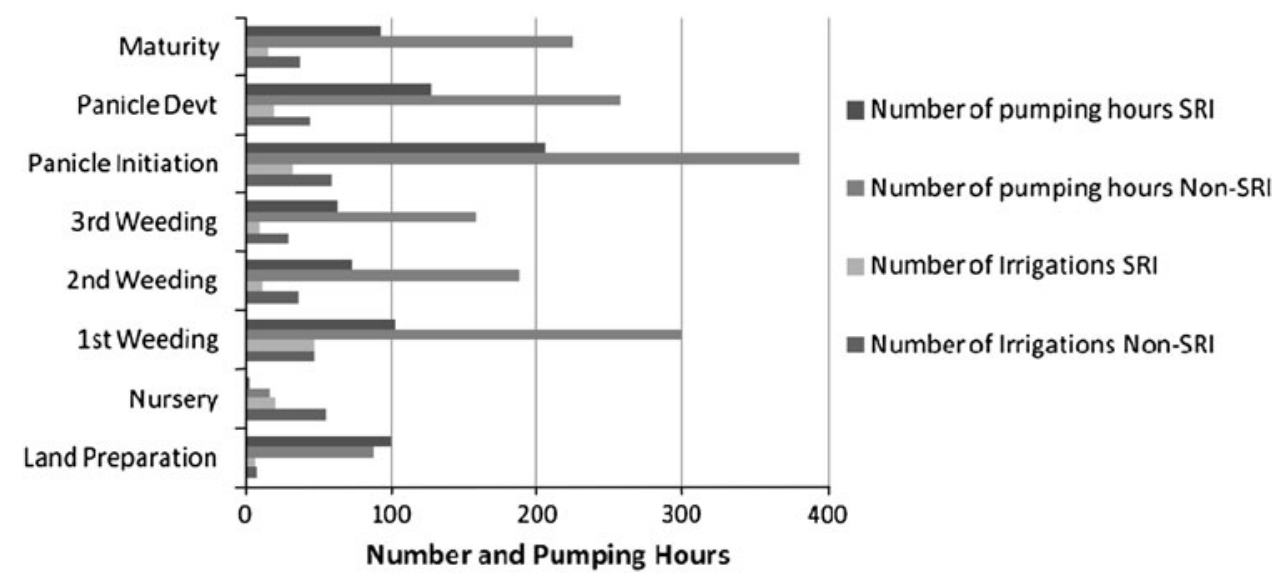


Table 5 Estimated water application in SRI and conventional paddy cultivation

\begin{tabular}{|c|c|c|c|c|c|c|c|c|}
\hline \multirow[t]{2}{*}{ Crop stage } & \multicolumn{2}{|c|}{$\begin{array}{l}\text { Number of } \\
\text { irrigations }\end{array}$} & \multicolumn{2}{|c|}{$\begin{array}{l}\text { Number of } \\
\text { pumping hours }\end{array}$} & \multicolumn{2}{|c|}{$\begin{array}{l}\text { Water application } \\
\left(\mathrm{m}^{3} \mathrm{ha}^{-1}\right)\end{array}$} & \multicolumn{2}{|c|}{$\begin{array}{l}\text { Cumulative water } \\
\text { application }\left(\mathrm{m}^{3} \mathrm{ha}^{-1}\right)\end{array}$} \\
\hline & Non-SRI & SRI & Non-SRI & SRI & Non-SRI & SRI & Non-SRI & SRI \\
\hline Land preparation & 7.4 & 6.3 & 87.9 & 99.5 & 2,198 & 2,488 & 2,198 & 2,488 \\
\hline Nursery & 54.3 & 20.5 & 16.3 & 2.7 & 407 & 67 & 2,605 & 2,554 \\
\hline 1st weeding & 47.0 & 47.0 & 298.8 & 102.0 & 7,472 & 2,549 & 10,077 & 5,104 \\
\hline 2nd weeding & 36.0 & 11.6 & 187.7 & 73.0 & 4,693 & 1,826 & 14,770 & 6,930 \\
\hline 3rd weeding & 29.6 & 9.9 & 158.1 & 62.8 & 3,952 & 1,570 & 18,722 & 8,500 \\
\hline Panicle initiation & 59.3 & 32.4 & 380.4 & 205.7 & 9,510 & 5,143 & 28,231 & 13,643 \\
\hline Panicle devt & 44.4 & 19.4 & 256.9 & 127.7 & 6,422 & 3,193 & 34,653 & 16,836 \\
\hline Maturity & 37.1 & 15.2 & 224.8 & 92.8 & 5,619 & 2,320 & 40,273 & 19,156 \\
\hline Total & 315.1 & 162.3 & 1610.9 & 766.2 & 40,273 & 19,156 & & \\
\hline Reduction between SRI and conventional & \multicolumn{2}{|c|}{$152.8(51.5 \%)$} & \multicolumn{2}{|c|}{$844.7(52.4 \%)$} & \multicolumn{2}{|c|}{$21,117(52.4 \%)$} & & \\
\hline
\end{tabular}

Fig. 5 Cumulative water applications in SRI and conventional rice cultivation

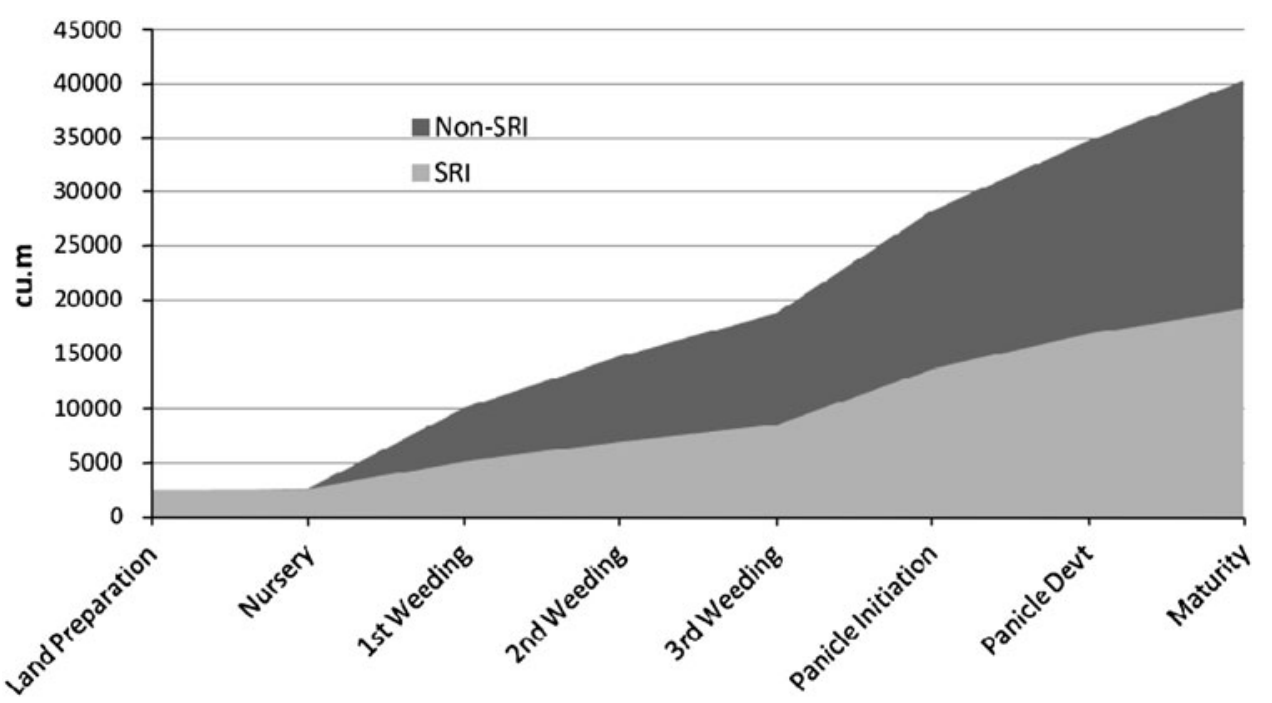

converted to SRI management following all of the principles.

Reduced extraction of groundwater and increased water productivity with SRI would be an additional benefit, having long-term implications for maintaining groundwater reserves where these are declining (as in Punjab and Haryana states). The opportunity for making savings in electricity, groundwater, seeds, etc. can justify more robust planning efforts for the promotion of SRI with appropriate investments and strategy to address the sources of resistance to its adoption. Partly these are attitudinal and informational, but also there would need to be some adjustments in the structures and facilities for irrigation, as well as in its organization and management, to be able to provide smaller amounts of water both regularly and reliably in place of the wasteful, costly, and unnecessary practice of continuous flooding. This is seen from China as well as India (Lin et al. 2009; Zhao et al. 2009).
Water use with SRI under tank irrigation systems

Tank irrigation systems are surface water-harvesting and irrigation systems. Many have fairly ancient historical origins and have been utilized for hundreds of years. Economic and social changes have contributed to many being now in a condition of disrepair and low productivity (CAD 2008). The experience discussed here pertains to a tank in Allapur village, having a traditional command area of 40 ha but only 28 ha are irrigated during the season due to insufficient filling of the tank. Seepage from the tank, leakages from the sluice, and different land types with varying characteristics within the command area make it difficult to estimate the actual quantities of irrigation water available to farmers.

The conventional system of irrigation from tanks operates in a simple way. A traditional water master, the neerati (the person responsible for distributing water), opens the 
sluice each day and allows water to flow continuously for a defined period of time, usually $8 \mathrm{~h}$, during the crop growth stages.

Detailed interviews with the neerati and season-long observations of the irrigation system provided some understanding of the differences in water use between SRI and conventional rice cultivation in tank command areas. Farmers in this tank system have taken up SRI on 27.53 ha, almost the entire tank command area. Water release was the same for SRI and conventional paddy during the initial 20-25 days for land preparation. However, after transplantation, the sluice was opened on alternate days for serving SRI fields while it is generally opened daily for conventional paddy.

The impact of SRI introduction, as gauged by the neerati, was that in spite of the low inflow to the tank during the year, he could provide irrigation to the total area and for the entire crop. The neerati also explained that closing the sluice in alternate days has led to substantial savings in water. Usually in tail-end areas, the crop suffers for lack of adequate water during the milking and maturity stages. Also some farmers resort to conjunctive use, with tubewells in the command area providing supplementary water during scarcity periods. With SRI, these problems were overcome. Rather than the usual 100 irrigations after transplanting, with SRI the neerati has completed the crop with about 50 irrigations.

As the entire command was not sown at one time, there are overlapping months, and not as much reduction was achieved as would be possible if crop calendars were more synchronized. The crop irrigation days in Allapur tank system were thus reduced from 125 to 75 irrigations. There is substantial scope for improving irrigation efficiency if the entire system were redesigned to suit alternate wetting and drying of fields. Laying out and modifying the field channels, introducing irrigation in blocks, insuring appropriate drainage, better control at the sluice, and planning for coordinated irrigation scheduling are some of the elements for tank system redesign to benefit most from the SRI opportunity.

\section{Conclusions and policy implications}

Based on a sample of farmers using SRI or conventional cultivation methods drawn from the same villages and operating under essentially the same conditions, this study has compared yield results, input use, economic returns, and water requirements and management. SRI farmers in the 2009-2010 season had an 18\% yield advantage, with a much higher increase in their net returns per hectare $(52 \%)$ due to reductions in the cost of production. There was a reduction of $19 \%$ in the straw yield on SRI farms, reflecting an increase in harvest index.

Contradicting the conventional belief that SRI is quite labor-intensive, the evaluation found a $43 \%$ decrease in labor costs. This was the largest contributor to a total decrease in costs of production with SRI, by about Rs. 9,187 ha ${ }^{-1}$. There can be initial difficulties in making labor market adjustments and in adapting to the management intensity of SRI. These can be interpreted as laborintensity. The seed and nursery costs are also substantially lower. As the overall usage of fertilizers and pesticides was low in the season, not much difference was observed in these inputs between SRI and conventional farms.

This study made a first approximation on the differences in water usage at field level between SRI and conventional rice production. It used the proxy variables of number of irrigations and pumping hours. Quantities of water used were estimated based on assumptions drawn from field observations and measurements. A purposive sample of 12 farmers taken from the main sample assessed comparable tubewell and groundwater situations.

The number of irrigations and pumping hours were 52\% lower with SRI than conventional crop management. Farmers could skip half of their irrigations during the crop season and still have higher yield and economic return. The estimated saving of about 845 pumping hours ha ${ }^{-1}$ amounted to a saving of $3,151 \mathrm{kWh}$ of electricity, which is currently totally subsidized by the state. This amounts to a saving of Rs. $12,607 \mathrm{ha}^{-1}$ given the cost of the power subsidy.

Saving of water with SRI in the field situation is observed to be higher than that reported from research station experiments, as present irrigation efficiency at field level is much lower. In tank irrigation systems, with SRI management, opening of sluice on alternate days was possible against the present practice of daily irrigation. This reportedly saved about 50 days of irrigation and enabled water to reach the tail-end farms, previously affected by inadequate supply. This study observed that there is further scope for improving irrigation efficiency in tanks by having more infrastructure investments and appropriate management.

At national level, we are seeing in India a shift away from conventional irrigation sources. Groundwater is becoming more important within the rice sector as surface irrigation is facing a serious deceleration in spite of heavy investments in the sector. Shifting of paddy to groundwater has precipitated a groundwater crisis in areas like Punjab as groundwater levels are falling, reducing water availability and raising the costs for production (Kang 2010).

With this backdrop, the results of this study have shown the potential of SRI for addressing multiple crises in India. With $90 \%$ reduction in seed costs, $36 \%$ lower labor costs, 
and $52 \%$ reduction in water use at field level, resulting in substantial electricity savings, SRI spread could be used at the same time to engender systemic improvements in rice production and resource management at the macro level.

Many evaluations of SRI have shown considerably greater yield increases than the $18 \%$ documented here. But even this yield advantage, coupled with reduced water use and cost reductions for farmers, could make SRI a vehicle for irrigation sector reforms. A planned national effort at promotion of SRI in combination with investments on improving irrigation systems and drainage, strengthening participatory institutions for management of irrigation and appropriate measures to regulate groundwater extraction can addresses several vexing issues simultaneously. Such a measure is also necessary for improving the national food security situation as a combination of irrigation and crop systems improvement will have high potential impact on rice production. The first approximations reported here should interest policy-makers and researchers in more thorough assessment of the water as well as economic impacts of SRI at local and macro levels.

Open Access This article is distributed under the terms of the Creative Commons Attribution Noncommercial License which permits any noncommercial use, distribution, and reproduction in any medium, provided the original author(s) and source are credited.

\section{References}

CAD (2008) Andhra Pradesh water reforms. Command Area Development Department, Govt. of Andhra Pradesh, Hyderabad. http://www.apwaterreforms.in/minorirrigation.aspx

Government of India (2007) National food security mission: operational guidelines. Department of Agriculture and Cooperation, New Delhi
Gulati A (2007) Re-energizing agriculture sector of Andhra Pradesh: from food security to income opportunities. International Food Policy Research Institute, New Delhi

Jain AK, Muralikrishna Rao BM, Rama Mohana Rao MS, Venkataswamy M (2009) Groundwater scenario in Andhra Pradesh. WASHCost-CESS working paper no. 3. Centre for Economic and Social Studies, Hyderabad

Kang B (2010) Freebies and water woes: Punjab wants cheap power and water to feed India. Tehelka vol 7, p 25, June 26

Lin XQ, Zhu DF, Chen HX, Cheng SH, Uphoff N (2009) Effect of plant density and nitrogen fertilizer rates on grain yield and nitrogen uptake of hybrid rice (Oryza sativa L.). J Agric Biotechnol Sustain Dev 1:44-53

Mahendra Kumar R, Surekha K, Padmavathi Ch, Subba Rao LV, Latha PC, Prasad MS, Ravindra Babu V, Ramprasad AS, Rupela OP, Goud V, Muthu Raman P, Somashekar N, Ravichandran S, Singht SP, Viraktamath BC (2010) Research experiences on system of rice intensification and future directions. J Rice Res 2:61-71

Moser CM, Barrett CB (2003) The disappointing adoption dynamics of a yield-increasing, low external-input technology: the case of SRI in Madagascar. Agric Syst 76:1085-1100

Moyna, Mishra A (2010) Out of depth: Andhra's groundwater crisis and a trail of suicides. Down to Earth. Centre for Science and Environment, New Delhi, July 15-31. http://www.downtoearth. org.in/node/1539

Rama Rao CA, Kareemulla K, Dixit S, Ramakrishna YS, Ravi Shankar K (2008) Performance of agriculture in Andhra Pradesh: a spatial and temporal analysis. Technical bulletin, Central Research Institute for Dryland Agriculture, Hyderabad

Satyanarayana A, Thiyagarajan TM, Uphoff N (2006) Opportunities for saving water with higher yield from the system of rice intensification. Irrig Sci 38:99-115

Sinha SK, Talati J (2007) Productivity impacts of the system of rice intensification (SRI): a case study in West Bengal, India. Agric Water Manage 87:55-60

Zhao LM, Wu LH, Li YS, Lu XH, Zhu DF, Uphoff N (2009) Influence of the system of rice intensification on rice yield and nitrogen and water use efficiency with different $\mathrm{N}$ application rates. Exp Agric 45:275-286 